\title{
EL TURISMO EN LAS TRANSFORMACIONES URBANAS DE LAS CIUDADES MEDIAS: BURGOS Y LAS POSIBILIDADES DEL PROYECTO ATAPUERCA
}

\author{
Gonzalo ANDRÉS LÓPEZ \\ Departamento de Geografia. Universidad de Valladolid
}

En la actualidad, el binomio que asocia a la actividad turística con los núcleos urbanos parece haberse convertido en uno de los temas de mayor interés para cuantos nos desenvolvemos en el campo de trabajo referido al análisis de la ciudad. En un momento, a finales del siglo XX, en el que los núcleos urbanos viven realidades notablemente expresivas de una coyuntura de replanteamiento de su situación en el espacio más amplio, el turismo se ha convertido en una de las opciones por las que decidirse desde el punto de vista de las nuevas actuaciones sobre el medio social y cultural de una ciudad. Y más aún, en esta dimensión, el diseño, gestión, promoción y mantenimiento de iniciativas turísticas en un núcleo urbano ha pasado a ser una de las realidades con mayor incidencia en los procesos de transformación y remodelación de espacios tradicionales y de uso cotidiano por parte de los ciudadanos en otros momentos de la historia urbana.

Particularmente, las ciudades europeas y, más concretamente, las españolas expresan actualmente el resultado de un dilatado proceso de transformación y son el reflejo de una intensa actividad humana bajo la cual se ha ido consolidando el perfil y la imagen de cada núcleo. Siguiendo a Ortega Valcárcel, podemos decir que la ciudad es quizá el exponente más claro de lo que este autor denomina el patrimonio territorial, un bien complejo, diverso y cambiante pero en el que queda patente un largo proceso de actuación humana sobre el medio en el que las comunidades han desarrollado sus actividades a lo largo del tiempo. En el territorio se mantienen las huellas de la propia civilización y en él quedan los testimonios de cada conjunto de individuos en cada momento concreto, creando una herencia que constituye el patrimonio cultural de un espacio, materializado en el caso de la ciudad en un conjunto de edificios, calles, plazas, trazados y elementos que vienen a formar, en suma, el verdadero ser vivo en el que se desarrollan la vida y las actividades de un conjunto de seres humanos. De este modo se entiende que en el denominado patrimonio territorial se incluye "no sólo el objeto edificado sino la construcción del espacio, más allá del edificio" (ORTEGA, 1999, $33)$.

Como tal elemento vivo, la ciudad se modifica y se reconstruye constantemente buscando siempre una nueva perspectiva en el uso y aprovechamiento de las distintas posibilidades que tenga en cada momento histórico. Es más, podríamos decir que la ciudad necesita de un elemento definitorio, de una función primordial que la delimite y le otorgue sentido en el conjunto más amplio al que pertenece. Tradicionalmente, se ha hablado de ciudades religiosas, ciudades militares

Polígonos, $\mathrm{n}^{\mathrm{o}}$ 10, 2000, pp. 9-35. 
o ciudades industriales y, más recientemente, de ciudades de servicios o ciudades de la comunicación y la información, y es que cada espacio urbano, en cada momento evolutivo, ha tenido un conjunto de actividades con sus consiguientes realizaciones espaciales que han definido la imagen de la ciudad. En concordancia con ello puede entenderse que la actividad turística en las ciudades haya estado marcada, en gran medida, por este tipo de función o de imagen ya que la ciudad ofrece una serie de elementos atractivos al visitante en relación no sólo con su patrimonio, en el sentido más estricto del término, sino también con cargo a la propia actividad que la define y las imágenes o símbolos que la representan.

En realidad, la imagen de una ciudad se va forjando con el paso del tiempo a medida que van quedando en ella distintos símbolos, diferentes elementos urbanos que, en suma, otorgan una personalidad específica a cada espacio. Algunos símbolos se construyen de manera intencionada con el fin de "hacer imagen urbana" y de representar a través de ellos elementos significativos de la vida de la ciudad en ese momento. El ejemplo más utilizado en este sentido sea quizá el de las espléndidas catedrales medievales que, unidas a otros elementos del patrimonio histórico-artístico, se han constituido como el componente más importante de buena parte de las ciudades de nuestro país desde el punto de vista de la oferta cultural y turística hacia el exterior. Pero en la ciudad no sólo se construyen los símbolos sino que este tipo de imágenes urbanas también adquieren significado con el paso del tiempo y "pasan a ser utilizados como emblemas" de una colectividad dada la utilización cotidiana de los mismos por parte de los individuos que habitan cada núcleo (JUARISTI, 1999). Tal y como justifica este autor, en cualquier etapa de la ciudad se advierte este tipo de "producción de símbolos urbanos". Desde las catedrales, fieles reflejos del poder jerárquico y rígido en una sociedad finalizada por la cúpula eclesiástica, hasta las propias instalaciones industriales del siglo XIX como manifestación de una actividad dominante en la función de los núcleos urbanos en ese momento, lo cierto es que la historia evolutiva de la ciudad queda definida por la aparición intencionada o inducida de elementos urbanos singulares.

Ahora bien, la ciudad actual es un complejo puzzle en el que se mezclan todas

y cada una de estas imágenes, que la historia de las actividades económicas y del ser humano ha ido legando, con la propia evolución y la nueva producción de símbolos. Hoy en día, la ciudad basa su oferta turística en un complejo conjunto de elementos de entre los que destacan las imágenes tradicionales pero entre los que surge con fuerza la necesidad de dotarse de símbolos modernos. Algunos autores señalan muy acertadamente cómo la clave del turismo en los núcleos urbanos ha de ser "un producto compuesto que asocia la ciudad y sus componentes internos y que se sustenta en la coordinación de ofertas" (VERA y DÁVILA, $1995,161)$. Y en esta dinámica la aparición de las ideas de promoción de la ciudad a través de una nueva simbología ha tenido en España una notable repercusión.

\section{TRAS LA ESTELA DE BILBAO Y BARCELONA: CULTURA Y TURISMO EN LAS CIUDADES MEDIAS ESPAÑOLAS.}

La crisis y reestructuración de uno de los pilares más importantes de la organi- 
zación de las actividades económicas en los núcleos urbanos, la industria, y la tendencia a una economía terciarizada han impuesto a la ciudad nuevas pautas desde este punto de vista. Hay nuevos factores que inciden en la necesidad de dotarse de nuevas imágenes por cuanto que los elementos que sustentan algunos de los más tradicionales han entrado en una fase de pérdida de importancia o, al menos, de replanteamiento. En este nuevo escenario, los servicios parecen obligados a ser la actividad económica que genere símbolos e imágenes urbanas por cuanto que se trata de la función que explica el sentido de buena parte de la economía actual y su incidencia en las ciudades. El proceso va más allá, y es que la producción de una imagen de cara al exterior se ha convertido en un elemento valorado en la gestión de la propia ciudad, ya no sólo por su significado meramente turístico sino también desde un punto de vista económico e incluso político. Podríamos decir que en nuestro país se empieza a formar una cierta cultura de la imagen urbana en la ciudadanía que entiende positivamente la gestión de una ciudad construyendo nuevos elementos que "actualicen" la tradicional imagen de su núcleo.

En este proceso, los equipamientos urbanos se han constituido como nuevos elementos generadores ya no sólo de una nueva imagen urbana sino también como verdaderos reestructuradores del entendimiento espacial de la ciudad. De hecho, las nuevas imágenes urbanas han generado no únicamente una nueva simbología de cada núcleo sino también una modificación de la centralidad en su interior generando recientes polos a considerar en la estructura de la ciudad. Un variado elenco de actividades, que pueden ser englobadas bajo el epígrafe genérico de lo que hoy venimos a conocer como Cultura, ha pasado a reflejarse en el espacio con la construcción de edificios representativos, dotados, modernos y accesibles, verdaderos equipamientos para la ciudad y auténticos signos de una nueva etapa en la construcción de los núcleos urbanos. Una etapa en la que se materializan los paradigmas de lo que se ha venido a denominar como postmodernismo urbano, y en la que la cultura surge de una relación permanente del presente con el pasado, reinterpretando en muchas ocasiones la grandeza y el significado de las tradicionales representaciones de la ciudad (ORTEGA, 1999).

En España encontramos dos claros ejemplos de este proceso en el que la nueva cultura urbana postmoderna ha llevado a la reinterpretación de la ciudad. Se trata de los conocidos casos de Bilbao y Barcelona, dos ciudades que mediante dos vías distintas han optado por transformar espacios tradicionales destinados en otros momentos de su historia a la realización de actividades de notable magnitud económica y social en el núcleo, pero que en los años 90 se han visto afectados por procesos de abandono y falta de planificación tras la crisis industrial. La propia existencia de grandes espacios urbanos sin uso y en un proceso de profundo deterioro ha llevado, en ambos casos, a optar por la revitalización urbana mediante el diseño de nuevos elementos destinados a la promoción turística de las ciudades, pero en una estrategia definida en la que se trata de revitalizar el conjunto urbano en general.

En Bilbao, el proceso comienza en el año 1988 con el inicio de las obras del nuevo transporte ferroviario subterráneo y se desarrolla, fundamentalmente en los años 90, con la redacción de un nuevo Plan General de Ordenación Urbana acorde a las nuevas necesidades manifestadas por la grave crisis económica y social 
de un núcleo tradicionalmente centrado en el peso de la actividad industrial. Es, sin embargo, la constitución de la Sociedad Bilbao Ría 2000 en el año 1992 el elemento decisivo que marca la pauta para la construcción de un nuevo Bilbao ya que, en un marco de dialogo y colaboración interinstitucional, se termina por promover la construcción del conocido Museo Guggenheim y del Palacio Euskalduna. Ambos edificios se han convertido ya en los elementos más significativos e imagen de marca de una estrategia muy amplia y ambiciosa en la que se tiene muy en cuenta la mejora de la movilidad interna en la ciudad. De ello son testimonio las actuaciones ya ejecutadas y en desarrollo de las operaciones de Abandoibarra, Amétzola o la Variante Sur Ferroviaria de Bilbao, con las que no sólo se recuperan espacios tradicionales fuera de uso generando nuevas centralidades en la ciudad, sino mediante las que se consigue finalmente la pretendida intermodalidad en el transporte urbano de la capital vizcaína. Y todo ello en una estrategia en la que la ría de Bilbao se fortalece como símbolo de la ciudad mediante la creación de los nuevos elementos singulares que la jalonan (OTAOLA, 1994).

En el caso de Barcelona, mediante una iniciativa notablemente compleja y en la que se han involucrado todas las administraciones y agentes públicos y el grueso del empresariado privado, se desarrolla la tan tratada remodelación urbana de la ciudad como consecuencia de la organización de los Juegos Olímpicos de 1992. En un proceso que parte de la estrecha colaboración entre administraciones desde mediados de los años 80 al poner en marcha el Plan de Marketing Turístico para los Juegos y se consolida con la redacción del primer Plan Estratégico de Barcelona a comienzos de los años 90, se ha creado finalmente el Consorcio de Turismo de Barcelona como elemento gestor de las líneas básicas de promoción turística de una ciudad ya reformada y convenientemente dotada de imágenes y símbolos modernos en el reestructurado frente de costa que ha venido a conocerse como la zona de la Villa Olímpica (ANTÓN y LÓPEZ, 1997).

Aunque la extensión de este artículo no permite más que un somero detenimiento en los procesos descritos tanto en Bilbao como en Barcelona, se puede concluir que, en los dos casos, la cultura vinculada a la promoción turística de la ciudad se ha constituido como el nuevo elemento generador de espacios urbanos cualificados. Y es que en nuestro país, a lo largo de la década de los noventa, se ha podido comprobar como la cultura es a menudo considerada como una de las escasas actividades sustitutivas de la industria desde el punto de vista de la creación de elementos urbanos singulares en la ciudad (WOLFF, 1997). Esta dinámica se ha desarrollado igualmente en ciudades españolas del segmento superior del sistema urbano como Sevilla o Valencia pero ha quedado mucho menos definida, y se ha desarrollado de forma más dubitativa, en las ciudades de rango intermedio en las que podemos incluir a la práctica totalidad de las capitales provinciales y a algunos de los núcleos urbanos del territorio nacional no afectados por la extensión y la influencia de las áreas metropolitanas.

El objeto de este trabajo a partir de este punto se centra, precisamente, en abordar inicialmente, en una primera aproximación, el estudio de la forma en que se está produciendo el fenómeno de la generación de nuevos elementos urbanos singulares en relación con el turismo y la transformación de espacios urbanos tradicionales en las ciudades medias españolas y, más concretamente, en la ciudad de Burgos en la que nos detendremos monográficamente. De manera general, se 
puede decir que el significativo encabezado que otorga Joseba Juaristi a uno de sus artículos, en los que trata la remodelación y revitalización de Bilbao, acierta de pleno con una denominación que parece responder ajustadamente al proceso que se abre paso de forma importante en las ciudades españolas de tipo intermedio. Este autor alude a la expresión "aprendiendo de Bilbao", mención que nos parece tremendamente significativa de la dinámica desatada en muchas de las ciudades medias españolas que, de uno u otro modo, vienen a seguir la estela marcada por Bilbao, Barcelona, Valencia o Sevilla en lo referente a la nueva promoción de la ciudad mediante la revitalización urbana (JUARISTI, 1999). Y ello incluso aún cuando en muchas de ellas la crisis industrial no ha tenido la incidencia tan notable que ha manifestado en los núcleos de mayor tamaño. Se ha registrado, de hecho, la dinámica de relocalizar a la actividad industrial activa ubicada en el interior de los municipios hacia los polígonos de las ciudades o en espacios de borde con el fin de aprovechar urbanísticamente los solares liberados por este tipo de operaciones. Un suelo que, en muchas ocasiones, se utiliza como contenedor de algunas de las iniciativas promotoras de una nueva imagen urbana para este tipo de núcleos en una estrategia más amplia que intenta replantear su situación tradicional en el sistema urbano.

Concretamente, en los años noventa, son pocas las ciudades españolas superiores a los 150.000 habitantes que no se plantean al menos la consideración de su realidad urbana y las cuestiones o factores fundamentales que han de definir su estrategia para el futuro. Aunque, justo es decirlo, en la mayoría de ellas la figura del Plan Estratégico aún no ha cristalizado de manera efectiva, sí se detectan rasgos y tendencias que marcan la aparición de un nuevo modo de entender la planificación de la ciudad y de gestionar los espacios urbanos de cara al turismo. Lo cierto es que las pautas marcadas en cuanto a la realización de planes de ciudad, fundamentalmente resumidas en la colaboración sector público - sector privado y en la elaboración de un documento consensuado sobre los diferentes aspectos y oportunidades a las que se enfrenta la ciudad (urbanísticos, sociales, económicos, culturales, educativos, turísticos...), parecen comenzar a tenerse como referencia en la verdadera construcción de la planificación urbana en núcleos de tamaño medio.

Más allá de la propia planificación estratégica en sí, y adoptando quizá uno de los elementos representativos de la misma, en las ciudades medias si parece haber cristalizado de manera más clara la promoción de la cultura y de elementos urbanos singulares en relación a ella. La construcción de equipamientos vinculados a este fenómeno ha adquirido, desde este punto de vista, una doble función en estos núcleos: por un lado, la utilidad para los propios residentes al adecuar la ciudad e incrementar la calidad de vida y, por otro, la posibilidad de proyectar la ciudad hacia el exterior e incluir al nuevo centro de polaridad en los circuitos de visita turística más importantes (P ASCUAL, 1999). Aunque en esta dinámica, ciertamente, han quedado de lado buena parte de los objetivos de la planificación estratégica como visión integrada de la ciudad, lo cierto es que ha supuesto una tendencia ya consolidada en los últimos años desde el punto de vista de la cultura y el turismo en la promoción de actuaciones urbanas en espacios singulares de las ciudades de tamaño medio. Un conjunto de ciudades que desde hace tiempo viene siendo apuntado por diversos autores como el sistema de núcleos que arrojan 
"una posición más favorable a corto y medio plazo, simplemente en razón de su propia escala" (RODRÍGUEZ, 1989, 36).

Como constatación de estos hechos podemos fijarnos en la reciente y profusa tendencia desde el punto de vista de la construcción de museos y centros de exposición monográficos en el conjunto de las ciudades a las que nos estamos refiriendo. Tal y como nos señala Núñez Centella, en el año 1980 no había en España ningún museo de los que hoy venimos a llamar interactivos y en Europa existían únicamente dos, el denominado "Evoluon" de la empresa Philips en Eindhoven y el "Palais de la Decouverte" en París. Los grandes museos tradicionales y centros de ciencia no contaban entre sus salas con elementos que pudiesen llevar a entender a las exposiciones como verdaderos elementos interactuantes con el visitante (NúÑEZ, 1999). Pues bien, sin detenernos en lo que ha ocurrido en Europa, lo cierto es que desde esa fecha, en las ciudades medias españolas, y únicamente en lo referido a museos de ciencia, se han creado centros en más de una docena de núcleos vinculados en todos los casos a creación de nuevos edificios representativos de una imagen urbana ya sea mediante la recuperación, ya mediante la nueva construcción. Pamplona, Castellón, La Coruña, Alcobendas, Granada, Tenerife, Murcia, Cuenca, Málaga, Valladolid, San Sebastián, Mérida o Las Palmas son fiel reflejo de esta tendencia abierta en la creación de edificios singulares vinculados a la promoción turística de una ciudad mediante la enseñanza monográfica e interactiva de contenidos museísticos.

En el marco de este panorama, la ciudad de Burgos acomete recientemente un análisis detallado de su situación real en el conjunto del sistema urbano nacional y valorando las potencialidades de que dispone se plantea, por primera vez en su historia, los hitos fundamentales que ha de marcarse para conseguir dinamizar de forma importante su tejido productivo, conseguir una imagen de marca bien definida y promocionada hacia el exterior y dotar al espacio urbano y a sus ciudadanos de una nueva simbología con la que se identifique la nueva manera de entender el núcleo. Tras el cambio político experimentado en la ciudad en las pasadas elecciones municipales de Junio de 1999, Burgos ha puesto en marcha finalmente una serie de proyectos, iniciativas e ideas que en muchos casos aparecían en el sentir de buena parte de los profesionales que nos dedicamos al estudio de esta ciudad pero que, por uno u otro motivo, no conseguían hacerse efectivas. De entre todas ellas ha destacado la promoción definitiva de un Plan Estratégico para Burgos y la puesta en marcha de un conjunto complejo de ideas en torno a uno de los potenciales más importantes de cara al futuro de la capital en los próximos años: el aprovechamiento turístico y como imagen de marca de la ciudad de los yacimientos de Atapuerca.

\section{EL PROYECTO ATAPUERCA COMO EMBLEMA DE LA DINA- MIZACIÓN TURÍSTICA Y CULTURAL DE BURGOS.}

Burgos es una capital de provincia de tamaño medio (actualmente poco más de 167.000 habitantes) con una marcada tradición caminera, vinculada al peso del Camino de Santiago y a su propio emplazamiento, y con un significado importante, al igual que en otras ciudades peninsulares, de las instituciones eclesiástica y militar. La ciudad se ha caracterizado tradicionalmente por contar con un patri- 
monio artístico de un alto valor encabezado por una de las más importantes catedrales góticas del mundo, pero en el que también han destacado otros edificios y espacios que han terminado por constituirse como verdaderos símbolos de la ciudad hacia el exterior. La mayoría de sus iglesias, las puertas de la muralla medieval y los restos de su castillo, así como el Monasterio de las Huelgas Reales o la Cartuja de Miraflores han forjado una imagen urbana que se ha completado con el significado de otros elementos del paisaje de la ciudad como el Paseo del Espolón o el propio río Arlanzón.

Sin embargo, la imagen de Burgos ha quedado complementada por tratarse de un núcleo industrial y un centro de servicios como tal capital provincial. En el año 1964 fue declarada Polo de Promoción Industrial y la ciudad asistió a un verdadero revulsivo en su configuración llegando a casi doblar su población en apenas 15 años hasta el punto de que desde este momento se asistió a la "conformación de una nueva ciudad, una ciudad media vinculada al desarrollo aportado por la nueva actividad económica" (ANDRÉS, 1999). Su especialización económica concreta ha quedado así definida en relación a un sector industrial dinámico, equilibrado y con un peso muy significativo tanto en el empleo como en la inversión global de la ciudad. A comienzos de los años 90, el núcleo contaba con más de 18.000 empleos industriales y con un porcentaje de población activa ocupada en la industria superior al $30 \%$. Junto a este significativo peso de la industria, siguiendo un proceso similar al desarrollado en el resto de capitales de provincia españolas de este tamaño, Burgos se ha consolidado también como un centro de servicios que aglutina con capacidad a un territorio extenso y muy diverso en el que viven más de 350.000 personas.

En relación con ambas funciones económicas, las imágenes patrimoniales de la ciudad se han visto completadas por el significado que en el núcleo adquieren los polígonos industriales llegando a identificar a la ciudad con la enorme chimenea (más de 150 metros de altura) de una de las industrias más emblemáticas de la capital, La Cellophane Española SA, que paradójicamente desaparecerá pronto tras 50 años de actividad en el municipio siendo sustituida por nuevas imágenes urbanas. En cualquier caso, la personalidad de la ciudad hacia el exterior y su significado para el turismo han quedado determinados por su patrimonio, su cultura y la función económica determinante, la actividad industrial. A pesar de ello, Burgos nunca ha contado con una imagen suficientemente definida desde el punto de vista de la promoción exterior, uniendo en una misma concepción el mero desarrollo del turismo con una estrategia planificadora más amplia.

La ciudad siempre ha sido considerada como el segundo centro industrial de la región castellanoleonesa, tras Valladolid, y superando a ésta en algunas de las ramas de actividad en las que se especializa o en las características de dinamismo y potencialidad de su tejido de pequeñas y medianas empresas. Se ha considerado también que su patrimonio está dotado del suficiente valor como para el aprovechamiento rentable de este tipo de recurso en relación al turismo y, sin embargo, Burgos no ha conseguido integrarse plenamente en los circuitos de visita nacionales e internacionales estables. De ello es buena prueba que el grado de estancia media en la visita a la provincia supera en poco el día y medio y las pernoctaciones en la ciudad aún no han conseguido ser afianzadas. Actualmente, la provincia aglutina el $18 \%$ de las visitas (104.221 visitas/mes en verano) sobre el total de 
Castilla y León y rebasa levemente el 16\% de las pernoctaciones (163.355 pernoctaciones/mes en verano) con una variación interanual muy reducida (BOLETíN DE COYUNTURA TURÍsTiCA, JUNTA DE CASTILlA Y LEÓN, Julio 2000).

En cuanto al número y la procedencia de los turistas que visitan Burgos capital, podemos basarnos en un dato estimado según las consultas realizadas en las Oficinas de Información Turística del Ayuntamiento. Concretamente, en la oficina más céntrica de la capital, ubicada en el Teatro Principal de la ciudad, durante los 7 primeros meses del año 2000 se han recibido poco más de 7.000 consultas de las que prácticamente el $70 \%$ correspondían a visitantes de procedencia nacional. Específicamente, de las 4.714 consultas realizadas en esta oficina más del $26 \%$ respondían a visitantes de la propia región de Castilla y León mientras que el $18 \%$ corresponde con turistas de la Comunidad Autónoma de Madrid. En la visita de personas extranjeras a la ciudad destacan Francia que ocupa un $30 \%$ de todas las consultas de este tipo de turistas y, en un segundo plano, Alemania y el Reino Unido.

CUADRO 1. Número de visitas realizadas a la oficina de turismo del Teatro Principal de Burgos según número de consultas informativas. Enero-Julio 2000.

\begin{tabular}{|c|c|c|c|c|c|}
\hline \multicolumn{3}{|c|}{ Turistas Españoles } & \multicolumn{3}{|c|}{ Turistas Extranjeros } \\
\hline Procedencia & $\mathbf{N}^{0}$ & $\%$ & Procedencia & $\mathbf{N}^{\mathbf{0}}$ & $\%$ \\
\hline Andalucía & 452 & 9,59 & Francia & 708 & 30,20 \\
\hline Aragón & 236 & 5,01 & Holanda & 63 & 2,69 \\
\hline Asturias & 81 & 1,72 & Portugal & 138 & 5,89 \\
\hline Baleares & 10 & 0,21 & Alemania & 342 & 14,59 \\
\hline Canarias & 21 & 0,45 & Bélgica & 44 & 1,88 \\
\hline Cantabria & 75 & 1,59 & Reino Unido & 278 & 11,86 \\
\hline Castilla laMancha & 112 & 2,38 & Italia & 149 & 6,36 \\
\hline Castilla y León & 1.258 & 26,69 & Resto UE & 30 & 1,28 \\
\hline Cataluña & 358 & 7,59 & México & 58 & 2,47 \\
\hline Extremadura & 121 & 2,57 & Argentina & 111 & 4,74 \\
\hline Galicia & 146 & 3,10 & Chile & 5 & 0,21 \\
\hline La Rioja & 74 & 1,57 & Resto Hispanoam. & 154 & 6,57 \\
\hline Madrid & 871 & 18,48 & EE.UU. & 202 & 8,62 \\
\hline Murcia & 115 & 2,44 & Japón & 33 & 1,41 \\
\hline Navarra & 222 & 4,71 & Resto Países de Asia & 24 & 1,02 \\
\hline País Vasco & 241 & 5,11 & África & 4 & 0,17 \\
\hline Valencia & 321 & 6,81 & Australia & 1 & 0,04 \\
\hline Total & 4.714 & 100,00 & Total & 2.344 & 100,00 \\
\hline
\end{tabular}

FUENTE: Ayuntamiento de Burgos. Concejalía de Turismo y Festejos.

Aunque estos datos reflejan una realidad estimada desde el punto de vista de 
los turistas que acuden a la capital hay que tener en cuenta que el peso del turismo en la ciudad de regiones como País Vasco, Aragón o Navarra es también muy significativo proporcionalmente a su población. Aunque en niveles absolutos destacan ante todo Madrid, Cataluña y Andalucía, comparando el número de habitantes de cada comunidad con el número de turistas que acuden a Burgos se observa un peso creciente de las regiones más cercanas citadas. Así lo demuestra un estudio realizado por la Universidad de Burgos para el Ayuntamiento de la ciudad en el año 1998 en el que, mediante una muestra de encuesta a más de 2.500 turistas, se llegan a apuntar una serie de tendencias interesantes. En este sentido, en primer lugar hay que decir que el viaje a la capital se realiza de manera predominantemente privada, y se detecta claramente una notable falta de oferta complementaria desde el punto de vista de la cultura, algún gran elemento de la ciudad que permita retener al turista algo más que unas horas de paso por el centro.

El turista tipo no pernocta en Burgos sino que realiza una visita de unas horas en las que dispone de tiempo "suficiente" para conocer la ciudad. En este sentido, aunque los datos varían notablemente según la duración global del viaje realizado por el turista que visita la ciudad es destacable recoger como el $44 \%$ de las visitas no pernoctan en la ciudad sino que pasan en ella unas horas (20\%) o el día completo pero sin llegar a dormir en los establecimientos hoteleros de la capital (24\%). Y este dato teniendo en cuenta que el número de pernoctaciones se incrementa notablemente por el mero hecho de disponer de un turismo de procedencia exterior mínimanente consolidado y en el que los viajes de 7 a 15 días permiten pernoctar al menos una noche en Burgos. Lo cierto es que aunque la ciudad dispone de un turista medio de nivel adquisitivo alto, un nivel cultural también elevado y que llega a la ciudad atraído por el importante valor de su patrimonio y su belleza no parece encontrar los suficientes argumentos como para quedarse. Tal y como concluye el estudio citado "la visita parece agotarse pronto. Unas horas de permanencia en la ciudad en el viaje organizado, mucho más ambicioso en sus objetivos que el viaje particular. Un día, dos o tres para la mayoría de los turistas que deciden pernoctar. Falta aquello para retener al turista más días. La oferta cultural es escasa o inexistente, no encuentran viajes de ida y vuelta organizados a la provincia, echan de menos un museo de Atapuerca, gran reclamo turístico en estos días para Burgos" (CALDERÓN, DíEZ y MARTíNEZ, 1998, 155).

La superación de todos estos problemas desde el punto de vista de las necesidades del turismo y la conveniencia de promover soluciones consensuadas para promocionar en la ciudad respuestas a numerosas posibilidades que se le plantean desde diversos puntos de vista han hecho que finalmente Burgos haya puesto en marcha la redacción de un Plan Estratégico intentando dinamizar su imagen tradicional. Aspectos como la vivienda, el propio urbanismo, el empleo, la cultura, la educación, la actividad empresarial y el significado y papel de los poderes públicos se han unido en la promoción de este documento que había venido siendo reclamado por parte de la propia disciplina geográfica en la ciudad desde hace tiempo mediante los trabajos de la profesora Bernal Santa Olalla. Esta autora aludía a la necesidad de "seleccionar los objetivos más importantes y establecer un plazo limitado para conseguirlos mediante un consenso que permita aunar los intereses públicos y privados de acuerdo con la demanda ciudadana e intentar lograr 
la resolución de los problemas. Es decir, Burgos está demandando una planificación estratégica" (BERNAL, 1997, 1147).

Gracias a ésta y otras muchas aportaciones y esfuerzos, la Asociación Plan Estratégico de la Ciudad de Burgos se constituyó como tal el día 17 de Julio del año 2000 siendo participada tanto por el propio Ayuntamiento de la ciudad como por la mayoría de las empresas y agentes sociales del municipio. Aún en fase inicial, y con una aportación previa de 20 millones de pesetas, se encuentran en preparación los trámites necesarios para la redacción definitiva del documento en el que queden recogidas todas las aspiraciones de la ciudad para los próximos años. De entre estas, destaca sin duda la necesidad de promocionar Burgos en el contexto del panorama nacional y dotar al núcleo de una nueva imagen urbana que sea el elemento fundamental de su dinamización turística y cultural. En este sentido los avances parecen ir por delante de la propia planificación estratégica ya que los hallazgos arqueológicos de la cercana Sierra de Atapuerca se han consolidado como el elemento fundamental en la formación de un nuevo símbolo de Burgos, con el sentido de dotar a la ciudad de una nueva imagen que permita su inserción en los circuitos internacionales de visitas turísticas.

La importancia de lo que en los foros locales y regionales ha venido a denominarse ya como "el Proyecto Atapuerca" se pone en relieve si tenemos en cuenta un dato tan significativo como su propia aparición en la prensa o el interés que ha suscitado en Internet. En este sentido las noticias directamente relacionadas con los yacimientos, su gestión y su próxima promoción en Burgos son cotidianas en los periódicos locales (Diario de Burgos ha publicado más de 50 noticias anuales en relación con este fenómeno durante los últimos tres años, lo cual significa, al menos, una aparición semanal en prensa), al igual que es relativamente sencillo encontrar páginas en la red dedicadas al análisis de esta materia (en la página de Diario de Burgos referida a los yacimientos se ofrecen más de 40 enlaces dedicados a la misma temática) (www.diariodeburgos.es/atapuerca).

La magnitud científica de los yacimientos es, desde luego, incuestionable hasta el punto de que por parte del Consejo de Patrimonio Histórico Español se solicitase la inclusión de la Sierra como parte de la lista de bienes catalogados como Patrimonio de la Humanidad, pretensión que la UNESCO concedió el 30 de Noviembre del pasado año 2000. Se trata del conjunto arqueológico más importante del mundo por lo que se refiere a los restos humanos datados con una antigüedad de entre 200.000 y 800.000 años. En Atapuerca se encuentran, por tanto, restos de homínidos correspondientes al Pleistoceno Medio y al Pleistoceno Inferior, llegando incluso a barajarse la antigüedad superior al millón de años. Pero los hallazgos de la Sierra destacan fundamentalmente por la importancia cuantitativa y cualitativa de sus huellas en este periodo. En los yacimientos se concentran miles de fósiles de mamíferos y aves de diferentes especies, pero con una importancia singular destaca la localización de restos humanos. En el yacimiento de la Sima de los Huesos se han recuperado hasta el momento cerca de 3.000 fósiles humanos pertenecientes a, al menos, 32 personas distintas con una antigüedad superior a los 300.000 años, lo que supone más del $90 \%$ de todos los fósiles humanos europeos de ese periodo y un $85 \%$ de los restos humanos no craneales del mundo. A ello hay que añadirle la constatación de la evidencia del poblamiento en Europa hace más de 780.000 años con la aparición de 85 restos fósiles en el 
yacimiento de Gran Dolina que, por su especial morfología y caracteres, han llevado a la creación de una nueva especie, el denominado $H$. antecessor, el cual es considerado por los paleontólogos como el antecesor de H. sapiens y de los homínidos de la línea europea del Pleistoceno Medio y Superior. Ello ha supuesto rechazar la hipótesis tradicional del poblamiento europeo hace menos de medio millón de años (CERVERA, ARSUAGA, BERMÚDEZ y CARBONELL, 1998).

La relevancia de estos hallazgos y el aluvión de iniciativas, ideas, proyectos y posibilidades que se han despertado a su abrigo han hecho que la realidad urbana de la ciudad de Burgos haya sido realmente trastocada. Con la finalidad de dar a conocer mundialmente los yacimientos, en una estrategia en la que los tres codirectores de las excavaciones se han implicado profundamente continuando con su labor divulgadora desde este punto de vista, el Ayuntamiento de la ciudad y varias de las instituciones comprometidas con el fenómeno Atapuerca (Junta de Castilla y León, Ministerio de Educación y Cultura, Fundación Atapuerca, Asociación Cultural Amigos del Hombre de Ibeas/Atapuerca (ACAHIA), Ayuntamientos de Ibeas de Juarros y Atapuerca, Caja de Burgos, Cámara de Comercio e Industria de Burgos...) han puesto en marcha diversas actuaciones que comienzan a tener su significado en la capital. La exposición "Atapuerca. Nuestros Antepasados", fue visitada en el Museo Natural de Ciencias de Madrid por más de 200.000 personas en el año 1999 constituyendo el mayor éxito de la historia del centro; los propios yacimientos, en poco más de 8 meses, tras la puesta en marcha de las visitas organizadas, han sido visitados ya por más de 22.000 turistas; y en el mes de Julio del año 2000 se ha trasladado una parte de la muestra referida al Museo Provincial de Burgos con el fin de su exposición indefinida en la capital ${ }^{1}$.

La importancia de estas iniciativas ha quedado ya enmarcada en lo que José María Bermúdez de Castro ha venido a denominar como "el proyecto cultural de la ciudad para el siglo XXI", un proyecto que arranca desde comienzos de los años 90 con el inicio de la divulgación sobre este fenómeno mediante el diseño por parte del propio equipo investigador de Atapuerca de una exposición para el Pabellón de Castilla y León en la Expo de Sevilla 92 y la muestra permanente en el "Aula Emiliano Aguirre", primer director de las investigaciones, en el núcleo de Ibeas de Juarros. Tras estos hitos y la publicación de numerosos libros, artículos científicos, artículos en prensa e incluso algunos videos sobre la Sierra de Atapuerca, el equipo codirigido por el propio Bermúdez, junto con Juan Luis Arsuaga y Eudald Carbonell, se ha involucrado definitivamente en la promoción de los yacimientos como rasgo distintivo de la ciudad de Burgos. En este sentido, el equipo de investigación de Atapuerca consideró que la importancia de los restos arqueológicos "obliga a plantearse más que una serie continuada de proyectos de investigación, un programa científico a largo plazo......desarrollando un proyecto social y cultural... ...sumando diferentes sectores de la sociedad que han entendido perfectamente el profundo calado de los resultados científicos" (BERMúDEZ, 1999, 14).

En este marco, el Ayuntamiento de la ciudad ha acometido ya los primeros pasos para la creación en Burgos de un equipamiento urbano, un museo, en el que se concentren todos los conocimientos acerca de los yacimientos y se divul-

${ }^{1}$ Diario de Burgos, 1 de Junio y 7 de Septiembre de 2000. 
gue la importancia de sus conclusiones científicas, a la par que se resuelve una situación de indefinición urbanística de la ciudad y se dota a Burgos de un nuevo símbolo urbano que defina su imagen moderna y su estrategia de futuro desde el punto de vista del turismo.

\section{EL MUSEO DE LA EVOLUCIÓN HUMANA DE BURGOS: LA NUEVA IMAGEN DE LA CIUDAD.}

La creación de un museo destinado a la muestra y enseñanza de los contenidos y hallazgos de los yacimientos arqueológicos de Atapuerca ha sido una idea puesta en marcha a lo largo del verano de 1999 cuando el nuevo equipo de gobierno recién accedido al Ayuntamiento de la ciudad manifestó abiertamente la intención de convertir Atapuerca en la nueva referencia de Burgos a nivel internacional. Un detalle muy significativo desde este punto de vista se resume en el hecho de que la primera reunión mantenida por D. Ángel Olivares como alcalde de la ciudad, una vez tomada la posesión del cargo, se realizase, en los primeros días del mes de Julio, con el equipo director de las excavaciones de la Sierra. Desde entonces, el interés por convertir Atapuerca en la nueva imagen de la ciudad ha sido constante teniendo siempre como referencia las palabras del propio mandatario municipal en alusión a que "sería dar un salto cualitativo de las posibilidades turísticas de muestra ciudad. Con este museo podemos decir que habrá un antes y un después desde el punto de vista de la atracción turística"2.

Desde este momento, los pasos para la construcción del centro al que se denominará "Museo de la Evolución Humana" (en adelante MEH), han sido firmes y constantes. En el mismo mes de Julio de 1999 el Ayuntamiento de Burgos encargó la elaboración de una memoria detallada acerca de las posibilidades y características técnicas más importantes que habría de tener el museo. En Noviembre del mismo año D. Ramón Núñez Centella, Director del Museo de Ciencias de La Coruña, presentó al consistorio municipal el documento sobre el cual se puso en marcha la elaboración de una normativa básica para la convocatoria de un Concurso Internacional de Ideas referido a la construcción del nuevo museo en conjunto con un Auditorio y Palacio de Congresos y Exposiciones. El Ayuntamiento llegó incluso en ese mismo mes de Noviembre a registrar la marca del nombre del museo como un elemento de uso exclusivo para la ciudad de tal modo que la denominación de "Museo de la Evolución Humana" se convirtió en una marca española y comunitaria de uso restringido ${ }^{3}$.

A finales del mes de Enero del año 2000 se convocó el citado Concurso Internacional de Ideas con carácter restringido y al que, por decisión de los organizadores tras sondear varias posibilidades, fueron invitados cinco grandes arquitectos de prestigio internacional. A lo largo del año han visitado la ciudad y los yacimientos, con el fin de conocer el terreno sobre el que realizar la propuesta y los contenidos de la misma, los arquitectos sevillanos Antonio Cruz y Antonio Ortiz, el arquitecto cántabro Juan Navarro Baldeweg, el norteamericano Steven Holl, el japonés Arata Isozaki y el francés Jean Nouvel. Con autores de obras tan significa-

\footnotetext{
${ }^{2}$ Diario de Burgos, 6 de Julio de 1999.

${ }^{3}$ Diario de Burgos, 4 de Noviembre de 1999.
} 
tivas como el Instituto del Mundo Árabe y la Fundación Cartier en París (Nouvel), el Museo de Arte Contemporáneo de Helsinki y el Museo de Arte Moderno de Nueva York (Holl), el Estadio Olímpico y la Estación del AVE en Sevilla (Cruz y Ortiz), el Palacio de Congresos y Exposiciones de Salamanca (Navarro) o la Casa de las Ciencias de la Coruña (Isozaki) la calidad del nuevo edificio a construir parecía asegurada mediante esta convocatoria. En los ocho primeros días del mes de septiembre del año 2000 se presentaron las propuestas de cada uno de los concursantes al proyecto siendo valorada cada una de ellas en función del diseño, la funcionalidad, la inserción en el espacio urbano y la coincidencia con los objetivos determinados en el pliego de condiciones explicitado por el Ayuntamiento. La pretensión de encontrar un edificio compacto, integrado coherentemente con el espacio urbano ya construido, modular desde el punto de vista funcional y propiamente museístico, y que no presentase problemas técnicos en cuanto a su construcción, supuso el estudio detallado de todos los paneles y maquetas presentados por los arquitectos.

\section{Concurso Internacional de Ideas para el Solar de Caballería. Museo de la Evolución} Humana de Burgos.

Proyecto de Cruz y Ortiz (arriba izquierda) y proyecto de Steven Holl (arriba derecha). Proyecto de Jean Nouvel (abajo izquierda) y proyecto de Arata Isozaki (abajo derecha)

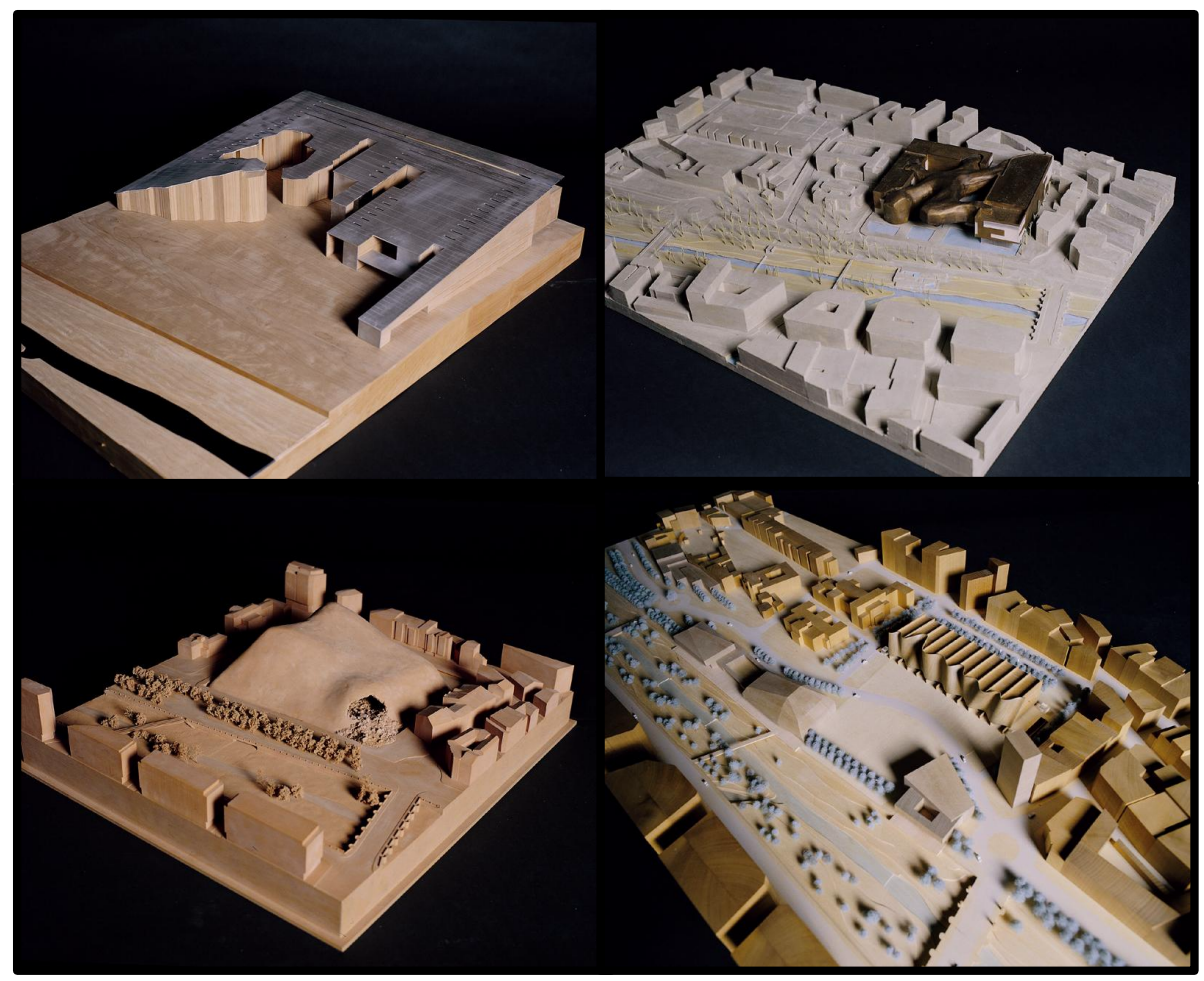

Fuente: Ayto. de Burgos. Concurso Internacional de Ideas para el Solar de Caballería de Burgos. 
La propuesta de los sevillanos Cruz y Ortiz se concretó en un edificio único dentro del solar, enfatizado por un plano de la cubierta con notable potencia y peso en la estructura del edificio que a través de formas dentadas conectaba con una gran plaza abierta en el frente del solar. Dividido en dos grandes áreas, una más dinámica y compleja, destinada al museo propiamente dicho, y otra dedicada al uso de Palacio de Congresos y Auditorio, el proyecto fue desechado por el Jurado debido a la propia escala del edificio y su relación con el entorno desde el punto de vista del propio tamaño.

El proyecto del norteamericano Steven Holl se concretó en una serie de edificios periféricos que albergaban los centros de investigación y las salas congresuales y expositivas, reservando el espacio central de formas orgánicas para el propio museo en una interpretación singular de la propia historia humana mediante esta estructura central del edificio. Asimismo, fue desestimado por el gran tamaño del conjunto respecto al solar y los problemas que planteaba la falta de espacios públicos, ya que la mayor parte de la superficie sobre la que se asentaba la estructura central se resolvía con la inclusión de laminas de agua.

El francés Jean Nouvel presentó la idea más revolucionaria diseñando una colina artificial que en su interior albergaba un espacio central sobre el que basculaban todos los usos propuestos y un conjunto de actividades comerciales añadido. Imitando el ambiente de una gran cueva y con una entrada similar a la de una caverna natural, enfocó el proyecto como una idea en la que la arquitectura era el soporte verde de una recreación de los propios yacimientos. Los problemas de viabilidad técnica y económica, así como la falta aparente de conexión con el exterior hicieron que esta original propuesta fuese también desestimada.

Dos fueron, sin embargo, los proyectos que suscitaron una mayor atención en el jurado y, posteriormente, en la propia opinión pública y en la de los profesionales dedicados al estudio de la ciudad. Por un lado, la idea presentada por el arquitecto japonés Arata Isozaki y, por otro, el proyecto, a la postre ganador, del arquitecto español Juan Navarro Baldeweg.

El proyecto con una mayor visión espacial de la ciudad fue, sin duda alguna, el realizado por el japonés Arata Isozaki, quien diseñó una idea cultural amplia que se ajustaba, en cuanto a dicha visión espacial, a la propiamente recogida en el pliego de condiciones del concurso, proponiendo una nueva ordenación de todo el conjunto urbano de los alrededores del solar en el que se ubican las propuestas, entre los puentes de San Pablo y Gasset. La división de los usos en varios edificios, dedicando al museo el contenedor más expresivo y en posición central, fue el mayor problema de una idea que, en conjunto, se presentaba como la que mayor visión urbana había tenido. La necesidad de reordenar toda la ribera del río Arlanzón en este sector de la ciudad, la construcción de un hotel en uno de los bordes de la propuesta y la importante renovación urbana que suponía una actuación fragmentada supusieron que el proyecto no fuese elegido.

Con ello se desestimó una actuación urbanística verdaderamente renovadora y que hubiese supuesto una auténtica referencia en cuanto a la forma de actuar sobre la ciudad. El proyecto del arquitecto japonés, pese a mostrar ciertos problemas desde el punto de vista de la funcionalidad, por otro lado siempre matizables, se mostró, desde luego, como el que mayores pretensiones de renovación urbanística tenía del conjunto del solar y su contacto con el río. En este sentido, se 
trataba del proyecto con un mayor compromiso en cuanto al cumplimiento de uno de los objetivos específicos del pliego de condiciones del concurso en el que se podía leer: "La propuesta incluirá: a) la ordenación urbana del ámbito de la margen izquierda del río Arlanzón comprendido entre los dos puentes"4.

Pese a cumplir este requisito, la dispersión funcional de los edificios y la importante reforma de la ribera del Arlanzón hicieron al jurado desestimar la posibilidad de haber acometido este proyecto, aún cuando se valorase el hecho de que el edificio concreto dedicado al museo supusiese "una propuesta clara y flexible de recorridos, espacios expositivos y servicios, atendiendo de una manera sencilla a la buena dimensión de los espacios anterior y posterior del propio mu$s e o "$. Con todo, se decidió que el proyecto presentado por Juan Navarro Baldeweg era el que mejor se ajustaba a las necesidades de la ciudad y a los objetivos pretendidos en la convocatoria del concurso. Este arquitecto planteó un edificio complejo pero en una única realización en la que se integran todos los usos de un modo ordenado pero polivalente y sencillo. El acceso al edificio a través de una gran rampa, que constituye un nuevo mirador inédito hacia la ciudad, se valoró en la misma medida que la posibilidad de realizar la entrada al museo desde esa posición prominente que obliga a descender al visitante simulando la visita a una cavidad.

De hecho, el edificio establece una relación con los propios yacimientos de la sierra y la trinchera del antiguo ferrocarril donde se llevan a cabo las excavaciones. Sin embargo, la razón fundamental por la que el Jurado se decantó por este proyecto fue la de que en él se reúnen, en una única propuesta que respeta la relación urbanística con su entorno, todos los usos propuestos y en una actuación flexible y con mucha modularidad desde el punto de vista del uso interno.

Más allá del propio contenedor de la idea, la imagen que definirá el nuevo símbolo de la ciudad vinculada a los contenidos de la evolución humana, en general, y a los yacimientos de Atapuerca, en particular, podemos detenernos en dos cuestiones fundamentales sobre las que entender el significado en Burgos de este museo: por un lado, el análisis de sus contenidos, sus objetivos, estructura y pretensiones como centro divulgativo de los conocimientos científicos y, por otro, la valoración de la localización elegida dentro de la ciudad y el significado urbanístico de la construcción de un edificio singular en el emplazamiento de un solar tradicional del conjunto urbano.

Por lo que se refiere a la primera cuestión, hay que destacar que las pretensiones del Ayuntamiento se centran en la construcción de un museo interactivo de ciencia en el que se muestren de manera detallada los principales conocimientos científicos y metodológicos relacionados con la evolución humana, aprovechando para ello la importancia mundial que en este sentido tienen los yacimientos burgaleses. Se pretende la realización de un centro dinámico y vivo que "supere el concepto tradicional de lugar de depósito y custodia de bienes" y en el que a través de réplicas de los yacimientos de Atapuerca, aplicaciones multimedia y re-

\footnotetext{
${ }^{4}$ Pliego de Condiciones de la Consulta Internacional para el Solar de Caballería de Burgos. Ayto. de Burgos. 2000, p 3, Carácter y efectos de la consulta.

${ }^{5}$ Consulta Internacional para el Solar de Caballería de Burgos. Acta Final del Jurado. Ayto. Burgos, 22 de Septiembre de 2000, p 3.
} 
producciones de los hallazgos se fomente el verdadero interés por el aprendizaje. En este sentido el MEH nace como un centro único en el mundo ya que se trata del primer museo interactivo dedicado en exclusiva a la evolución humana. Tal y como recoge Ramón Núñez en la memoria del proyecto es interesante entender como "además de la circunstancia única que supone la existencia de los yacimientos de Atapuerca, puede decirse que no existen precedentes en el mundo de un museo con esta temática concreta. Existen secciones de antropología en numerosos museos de Historia Natural y también en museos arqueológicos, así como hay en el mundo algunos museos de antropología dependientes de distintas universidades, sobre todo en los Estados Unidos; incluso existe algún pequeño museo sobre la Evolución, pero no conozco la existencia de ningún museo dedicado especificamente a la Evolución Humana, si exceptuamos el museo de Neanderthal, si bien con un ámbito temático y planteamiento mucho más limitado" (NúÑ̃E, 1999, 13).

\section{Concurso Internacional de Ideas para el Solar de Caballería. Museo de la Evolución Humana de Burgos. \\ Proyecto ganador: Juan Navarro Baldeweg}

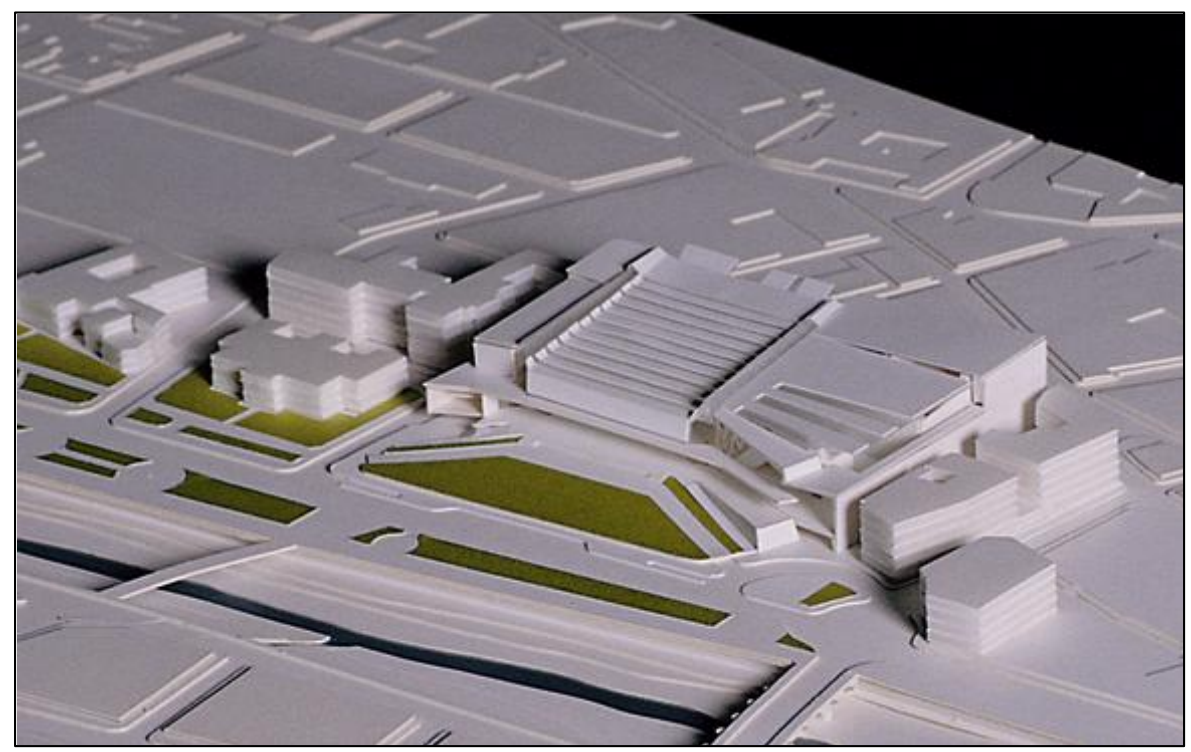

Fuente: Ayto. de Burgos. Concurso Internacional de Ideas para el Solar de Caballería de Burgos.

Bajo unas pretensiones tan ambiciosas el MEH de Burgos intenta responder así a cinco grandes objetivos:

- En primer lugar, la creación de un museo como centro educativo fomentando la enseñanza de la arqueología, la paleoantropología, la paleontología, la geología y la propia evolución humana. 
- En segundo lugar, la construcción de un gran centro de exposiciones destinado a mostrar los importantes hallazgos de los yacimientos de Atapuerca.

- En tercer lugar, la pretensión del museo de convertirse en un centro científico y universitario con espacios específicos para la investigación de distintos grupos de trabajo.

- En cuarto lugar, el MEH como elemento para el desarrollo de la ciudad de Burgos desde un punto de vista cultural dada la necesidad en la misma de disponer de un Auditorio y Palacio de Congresos y Exposiciones.

- Finalmente, el significado del museo como reclamo turístico para el exterior mediante la construcción de un edificio altamente significativo de la arquitectura de finales de siglo XX.

Para la consecución de estas metas se constituyó en Julio del año 2000 un comité de 13 expertos dirigido por Henry De Lumley, profesor del Instituto de Paleontología Humana de París, y en el que además de los tres codirectores de las excavaciones participan miembros de las Universidades de Harvard, California, París o Cambridge. Sobre la base de los informes emitidos por este comité se organizará el conjunto detallado de temáticas a las que habrá de referirse el museo aunque en la distribución de las salas y el diseño del edificio ya existen una serie de requisitos preestablecidos.

CUADRO 2. Superficies mínimas recomendadas para la construcción del Museo de la Evolución Humana de Burgos. 2000.

\begin{tabular}{|c|c|c|c|c|}
\hline \multicolumn{2}{|c|}{ Museo Evolución Humana } & \multicolumn{3}{|c|}{ Palacio Congresos, Exposiciones y Auditorio } \\
\hline Tipo Superficie & $\mathbf{m}^{2}$ & Tipo Superficie & Plazas & $\mathbf{m}^{2}$ \\
\hline Espacios Comunes & & Auditorio & & 12.500 \\
\hline Porche & 50 & Sala principal & 1.700 & \\
\hline Prevestíbulo & 70 & Sala polivalente & 600 & \\
\hline Vestíbulo y tienda & 220 & Otras salas & & \\
\hline Guardarropa & 30 & Cafetería & & \\
\hline Cafetería & 300 & Oficinas & & \\
\hline Aseos & 80 & Espacios comunes & & \\
\hline Salas Exposición & & Palacio Congresos & & 3.500 \\
\hline Salas Exposición Atapuerca & 2.500 & Despachos & & \\
\hline Salas Temporales Exposición & 500 & Zonas exposición & & \\
\hline Otras Salas & 260 & Salas prensa & & \\
\hline Otros & & Oficinas y almacenes & & \\
\hline Oficinas y despachos & 500 & Espacios comunes & & \\
\hline Área de Investigación & 4.000 & Comedor & 200 & \\
\hline Otros espacios & 170 & Salas Exposición & & 2.000 \\
\hline Total Espacio Útil & 8.680 & & & \\
\hline Total Espacio Construido & 10.400 & Total Esp. Construido & & 18.000 \\
\hline $\begin{array}{ll}\text { FUENTE: } & \text { AYUNTAMIENTO. D } \\
& \text { Caballería de Bur } \\
& \text { ción Humana de B } \\
& \text { Noviembre } 1999 .\end{array}$ & BURGOS: & $\begin{array}{l}\text { Onsulta Internacional de } \\
2000 \text { y NúÑ̃Z CENTELLA }\end{array}$ & $\begin{array}{l}\text { eas para } \\
\text { : Museo }\end{array}$ & $\begin{array}{l}\text { olar de } \\
\text { Evolu- } \\
\text { Burgos, }\end{array}$ \\
\hline
\end{tabular}


El proyecto pretende la construcción de dos grandes elementos: por un lado, el propio MEH y, por otro, un Auditorio y Palacio de Congresos y Exposiciones para la ciudad. El museo habrá de tener en torno a algo más de 10.000 metros cuadrados construidos que se distribuirán otorgando una especial importancia a las salas de exposición y a los espacios destinados a la investigación. De hecho, el Área Científica prevista supondrá unos 4.000 metros cuadrados mientras que a las salas de exposición se dedicarán más de 3.000 metros.

Además de la dotación común a cualquier equipamiento de este tipo, resumida en las características y superficies de los espacios comunes que pueden observarse en el cuadro adjunto, lo cierto es que el MEH destaca por la importancia de una Sala de Exposición permanente dedicada a la Evolución Humana subdividida, a su vez, en dos espacios destinados a la propia evolución en general y a Atapuerca, en particular. En estas salas pretende realizarse una reproducción a tamaño prácticamente natural de algunos de los yacimientos de la Sierra y ofrecer al visitante la posibilidad de vivir de forma idealizada los conceptos fundamentales de la evolución humana.

Con todo, el rasgo más destacable del nuevo centro es la pretensión de constituir en él con el paso del tiempo un Instituto Universitario Paleoantropológico mediante el afianzamiento progresivo de la investigación realizada en el propio museo. Para ello el equipo de investigación de Atapuerca ha defendido la necesidad de depósito de los restos de los yacimientos en el propio MEH de Burgos, una vez convenientemente dotado de laboratorios que permitan su adecuado análisis y tratamiento. Hasta el momento, tras finalizar las sucesivas campañas de excavación, los fósiles recuperados se depositan de manera temporal en los laboratorios de las Universidades que trabajan en el estudio de Atapuerca y en el Museo Nacional de Ciencias de Madrid, siendo necesario el correspondiente permiso de la Junta de Castilla y León por un tiempo determinado hasta que los restos se consignan al Museo Provincial de Burgos.

Con la construcción del MEH y según palabras de Bermúdez de Castro, "si el Museo de la Evolución Humana acoge todo el registro de Atapuerca y se habilitan además una serie de laboratorios (restauración, fotografia, microscopía, estudio, etc.) que permitan el tratamiento de los materiales, consideramos innecesario el transporte de los mismos a las instituciones anteriormente citadas. Los investigadores del EIA así como otros científicos españoles y extranjeros se desplazarian hasta Burgos para realizar in situ sus investigaciones sobre el material. La mejora en la calidad y rapidez de las comunicaciones haría factible esta novedad en las investigaciones sobre Atapuerca. Sería conveniente la construcción de una pequeña residencia en las proximidades del museo para la estancia temporal de investigadores. Esto permitiría crear un ambiente de investigación en torno al museo, quizás el embrión de un futuro Instituto sobre Cuaternario y Evolución Humana, vieja aspiración del EIA desde hace ya muchos años" (BERMÚDEZ, 1999, 17-18).

La importancia del MEH como centro investigador vinculado a la actividad científica de los yacimientos queda puesta de manifiesto en una estrategia de actuación que puede ser notablemente beneficiosa para la dinamización de la propia vida cultural e intelectual de la ciudad. Con el mismo fin se proyecta el otro gran equipamiento regulado en el Concurso Internacional de Ideas convocado por el 
Ayuntamiento, un Auditorio y Palacio de Congresos y Exposiciones con capacidad para 2.300 personas en dos salas, por lo que se refiere al Auditorio, y con una estructura dotada con más de 5.000 metros cuadrados destinados a exposiciones y salas congresuales. En suma, a los 10.400 metros previstos en el MEH se unirían los 18.000 proyectados en este segundo equipamiento totalizando más de 28.000 metros construidos en total. A ello hay que añadirle además la construcción de un aparcamiento subterráneo con capacidad para más de 1.000 plazas de turismo y 30 destinadas a autobuses.

Más allá de los datos, lo que se refleja es la verdadera pretensión de construir un gran equipamiento con el que dinamizar el turismo y la cultura en Burgos mediante un museo y centro investigador unidos por el nudo de Atapuerca. En relación con ello, se pretende crear un eje turístico y cultural entre los propios yacimientos y el futuro museo llegándose incluso a plantear para un futuro próximo la unión de los propias excavaciones y el centro mediante una línea de tranvía o tren de cercanías cuya realización está siendo estudiada por el Ayuntamiento de Burgos y la Junta de Castilla y León. No cabe duda de que las posibilidades que ofrece el museo para la ciudad son muy importantes y que mediante la potenciación del Proyecto Atapuerca se consolida en Burgos una estrategia definitiva de potenciación del turismo y la cultura en la ciudad. Ahora bien, desde el punto de vista de la Geografía como ciencia y el interés que despiertan en ella los procesos con reflejo espacial en la ciudad, es oportuno por nuestra parte valorar cuál es el significado del propio equipamiento y el nuevo símbolo que supone dentro del espacio urbano de la ciudad de Burgos. Hemos de referirnos, por tanto, a la segunda de las cuestiones que comentábamos líneas atrás, la del propio emplazamiento del museo en un solar tradicional de la ciudad y el valor de la actuación urbanística llevada a cabo con la construcción de este equipamiento.

En este sentido, el MEH de Burgos va a construirse en uno de los solares más emblemáticos y significativos de la ciudad tanto por lo que se refiere a su mera localización, como por lo que toca al tipo de uso tradicional que ha tenido y los problemas habidos en su gestión urbanística durante los 20 años pasados. El espacio conocido como "Solar de Caballería" albergará en una parcela de poco más de 23.000 metros cuadrados de superficie los equipamientos señalados y con las características propuestas pretendiendo que no sólo se consiga la promoción de un edificio moderno y simbólico sino también integrado con la ciudad. En este sentido, el Concurso de Ideas convocado afecta no únicamente a la construcción del propio edificio sino que también incluye un entorno de ordenación mediante el que realizar un tránsito hacia la ciudad ya consolidada.

Tal y como se puede ver en el plano, Burgos se caracteriza por el asentamiento inicial de la ciudad histórica en la falda del Cerro del Castillo, en el valle medio del Arlanzón que en este punto estrecha su lecho cerrado por varios cerros testigo tanto al Norte como al Sur del propio curso. El centro histórico de la ciudad, delimitado en el plano por los límites de la antigua muralla, se constituye como el embrión a partir del cual se va a formar la ciudad media que Burgos ha llegado a ser actualmente. Hasta el siglo XIX la ciudad superó en poco los límites de la muralla limitándose a iniciar su extensión hacia el sur y oeste a través de sendos arrabales que seguían la línea marcada por las principales vías de comunicación y los más importantes centros religiosos. La construcción del ferrocarril Madrid - 
Irún a su paso por la ciudad vino a sumar una barrera añadida al río y a los cerros que limitan el valle de tal modo que Burgos configuró definitivamente una forma alargada, longitudinal y en sentido este-oeste vinculada al propio emplazamiento del centro histórico y al paso por la ciudad del Camino de Santiago.

El crecimiento durante la primera mitad del siglo XX es paulatino pero sin abarcar una gran extensión superficial, limitándose a la configuración definitiva de un espacio urbano extendido al sur del río y al norte del ferrocarril, además de iniciarse la expansión de la ciudad hacia el este. El verdadero crecimiento de Burgos se concentrará espacialmente al norte del Arlanzón y al este del centro histórico, consolidando un centro funcional que es hoy en día el verdadero corazón económico de la ciudad. Gracias al desarrollo industrial desde mediados de los años 60 se formará definitivamente la estructura urbana actual en la que el centro histórico ha sido levemente desplazado por el centro funcional como tránsito hacia el barrio de Gamonal y el polígono del mismo nombre (ANDRÉS, 1999).

Como puede deducirse a simple vista observando el plano, la ubicación del Solar de Caballería en el conjunto de esta estructura urbana es inmejorable para la construcción de un equipamiento urbano destinado a toda la ciudad y a la visita exterior. El solar se localiza en un conjunto tradicionalmente deteriorado desde el punto de vista de la imagen urbana y caracterizado por haberse consolidado como un espacio no totalmente integrado en la ciudad por situarse al sur del río, de modo que el primer significado del MEH puede ser la revitalización de la propia zona sur de Burgos.

Solar De Caballería de Burgos. Plano de situación en la ciudad.

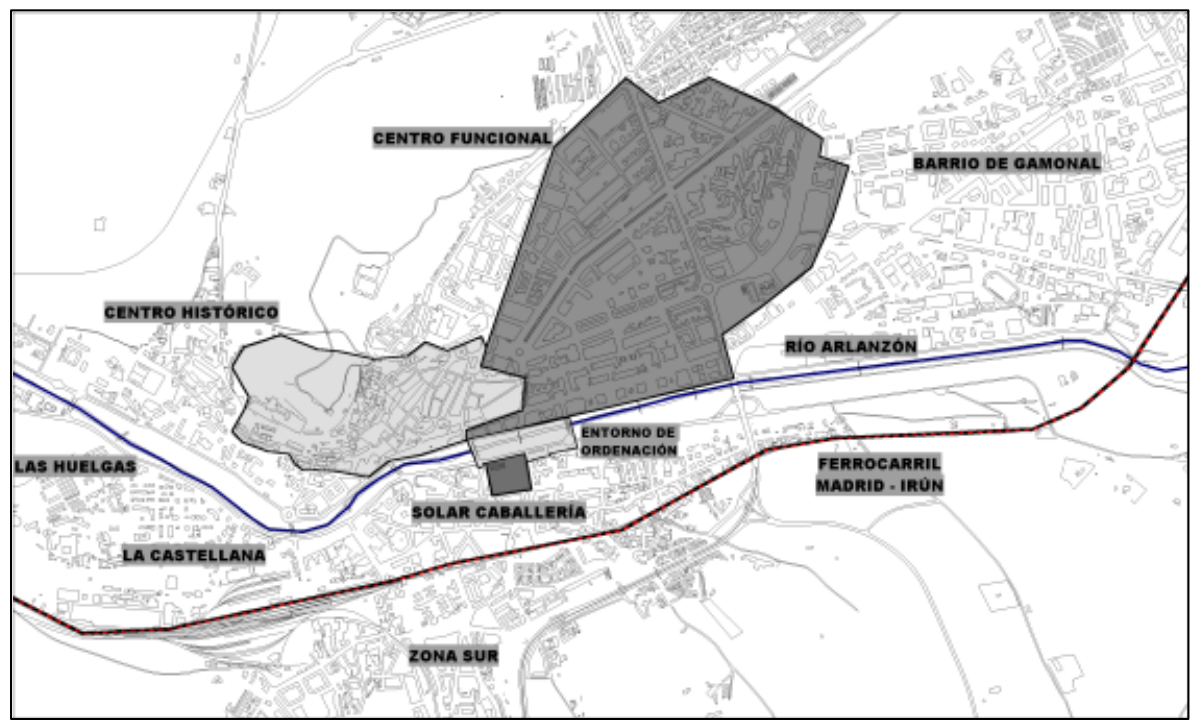

Elaboración propia 
Por otro lado, el espacio destinado a la construcción del museo se localiza en la ribera del río, muy cercano tanto al centro histórico como al centro funcional de la ciudad actual así que puede constituirse como un nexo de unión entre ambos elementos con el sur de Burgos facilitando el equilibrio interno de la ciudad. Con ese fin se pretende la citada urbanización del contacto del solar con el río y su tránsito hacia el norte del curso fluvial. Desde un punto de vista estético y arquitectónico, la cercanía de algunos de los monumentos más destacados de la ciudad, fundamentalmente la propia Catedral, supone que el Museo de la Evolución Humana haya de entenderse como un contrapunto actual al significado simbólico del patrimonio tradicional de Burgos, pretendiendo establecer incluso un diálogo espacial con el monumento medieval más importante del núcleo.

Finalmente, hay que apuntar que la construcción del MEH supone gestionar tras más de veinte años de dudas la solución urbanística para el solar al que nos estamos refiriendo, un espacio que ha quedado definido por una verdadera sucesión de propuestas, ideas, proyectos e indecisiones sobre su destino final en la ciudad de Burgos. En este solar ubicado al sur del río estaba construido tradicionalmente el Convento de San Pablo perteneciente a la Orden de los Predicadores Dominicos, contando con una iglesia gótica de alto valor artístico y aglutinando, hasta los inicios del siglo XIX, la organización urbana de este sector de la ciudad.

\section{Usos en el Solar de Caballería de Burgos: Cuartel de San Pablo (años 60).}

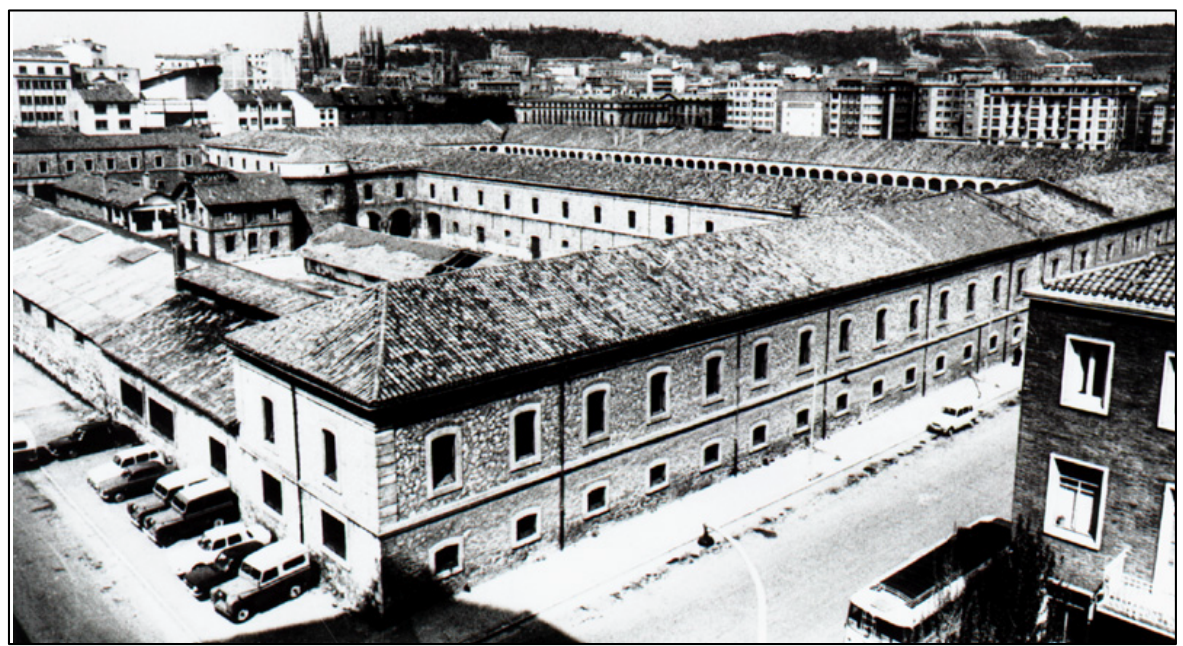

Fuente: Archivo Municipal de Burgos, Expediente AD-821/1 y Ayuntamiento de Burgos.

Durante la ocupación francesa de Burgos el convento fue asaltado y ocupado por las tropas militares produciéndose graves deterioros en su estructura. En la primera mitad del siglo XIX las propiedades fueron desamortizadas y finalmente, desde el 5 de Septiembre de 1842, pasaron a ser propiedad del Ramo de Guerra del Ministerio del Ejército tras la cesión efectuada a éste por el Ministerio de 
Hacienda. En 1870, el Ejército español, en el marco de formación de un nuevo Estado centralista y considerando la posición estratégica de Burgos, aprobó la construcción de diversos cuarteles en la ciudad de entre los que destacaba el denominado Cuartel de San Pablo destinado a la Caballería Militar. Como consecuencia de ello se levantó definitivamente el Cuartel de Caballería de San Pablo que daría nombre al solar sobre el que hoy se pretende construir el museo y que puede observarse en la fotografía poco antes de su demolición casi un siglo más $\operatorname{tarde}^{6}$.

\section{Usos en el Solar de Caballería de Burgos: parking de vehículos (años 90).}

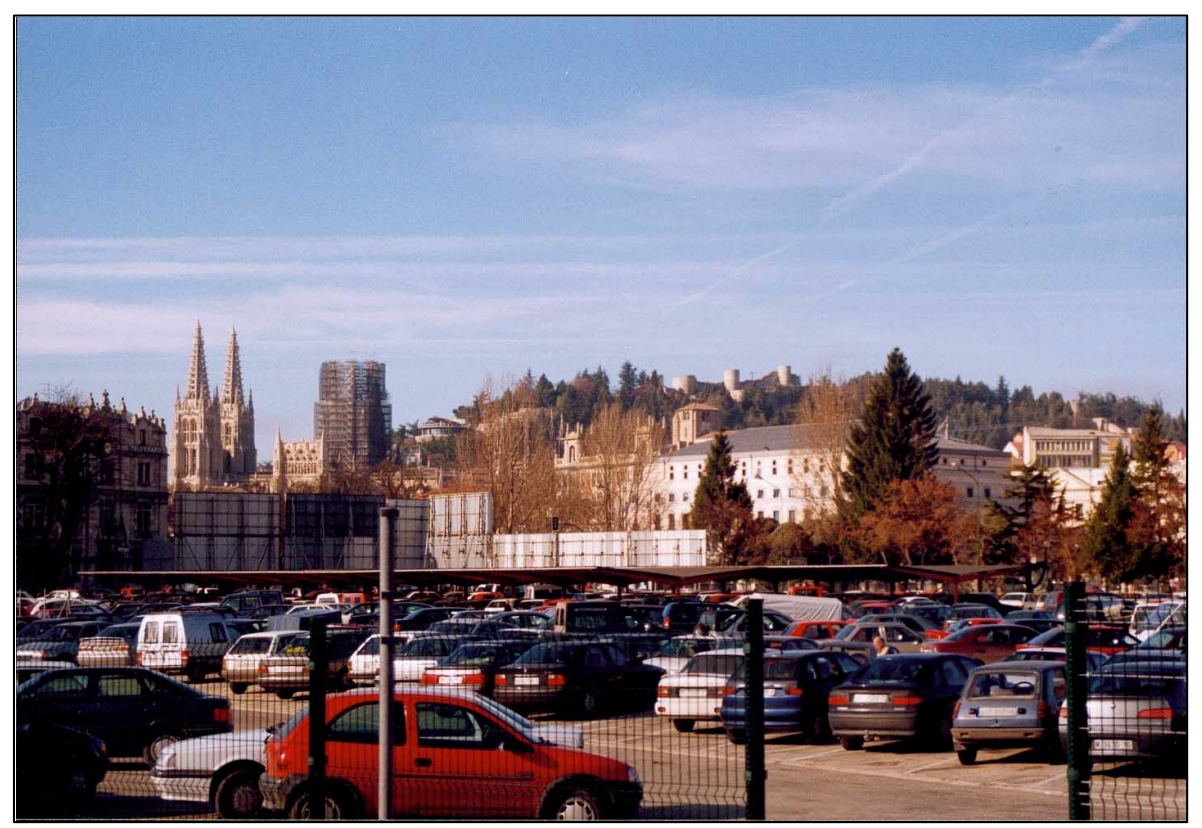

Fuente: Archivo Municipal de Burgos, Expediente AD-821/1 y Ayuntamiento de Burgos.

La modernización del ejército en España, la mejora de la economía y la propia apertura política y económica que vivió España a partir de mediados del siglo XX hicieron que en buena parte de las capitales de provincia se plantease la reconsideración de la situación de la institución militar en el interior de los núcleos. En Burgos, desde comienzos de los años sesenta comenzó a plantearse una actuación concreta a la que se denominaría en la ciudad con los desorbitados calificativos de "la operación urbanística del siglo, el problema del siglo o la obra sustancial del siglo" mediante la cual se pretendía desplazar los cuarteles militares del interior del núcleo a otros espacios más alejados de la vida urbana.

Desde mediados de 1964 el Ayuntamiento comenzó a plantearse la posibilidad

\footnotetext{
${ }^{6}$ Archivo Municipal de Burgos, Expediente AD-5256/1.
} 
de comprar los cuarteles al Ministerio del Ejército, los cuales fueron adquiridos finalmente por la Caja de Ahorros Municipal en una suerte de movimientos urbanísticos que superan con mucho las pretensiones de este trabajo pero que abordaremos en investigaciones posteriores. Sin entrar en los detalles, lo cierto es que la Caja de Ahorros Municipal de la ciudad compró finalmente toda la superficie de los cuarteles de Burgos tras la firma de un convenio el 23 de Octubre de 1972 y mediante escritura notarial de 5 de Febrero de 1973 por poco más de 200 millones de pesetas llegando a un acuerdo con el Ayuntamiento de la ciudad para la cesión del Solar de Caballería. La propia entidad de ahorro promovió la gestión de un Plan Parcial para la construcción de viviendas en el Solar de Caballería en el año 1974 y, tras su cesión al Ayuntamiento, el Servicio Municipalizado de Desarrollo Urbano y Fomento de la Construcción encargó al arquitecto Antonio Perpiñá la redacción definitiva del Plan de Ordenación del solar con uso alternativo residencial y comercial?.

Ninguna de las ordenaciones previstas se llevaría a cabo y a lo largo de los años 70 se sucederían diferentes propuestas que, por intereses municipales en unos casos, particulares en otros, y por la propia dificultad introducida por el Plan General de Ordenación Urbana vigente entonces en el municipio, estarían abocadas al fracaso. Desde la construcción de un "Gran Hotel de Burgos", pasando por la instalación en el solar del Edificio Central de Telecomunicaciones y Correos, la construcción de un Instituto, la promoción de un "centro cívico comercial y de negocios" o la más mundana idea de levantar uno de los edificios comerciales de la firma "El Corte Inglés", lo cierto es que el Solar de Caballería ha sido siempre uno de los espacios de la ciudad, por su tamaño y su localización, predestinado para acoger un gran equipamiento.

Con todo, tras la multitud de propuestas y proyectos baldíos el Ayuntamiento decidió considerar al solar como "lugar idóneo de emplazamiento para aparcamiento de vehículos, con carácter provisional". Una provisionalidad que ha durado más de 21 años ya que desde la aprobación de este uso por parte de la Comisión Municipal Permanente del propio Ayuntamiento el 11 de Julio de 1979 hasta la actualidad el solar se ha destinado, primordial y casi exclusivamente, para albergar un parking de vehículos en superficie ${ }^{8}$.

Tras ese dilatado margen de tiempo ha surgido finalmente el proyecto que parece haber consensuado intereses y acercado posiciones y que finalmente se está promoviendo para la construcción del citado Museo de la Evolución Humana en este solar. Un espacio ejemplar dentro de Burgos, tanto por su situación como por su historia urbana y económica, un espacio que resume la propia historia de la ciudad y sus avatares a lo largo de su evolución. De albergar un centro monástico en un entorno semirural y de huertas, el solar acogió uno de los centros de poder más importantes del núcleo durante muchos años, el Cuartel que muchos de los habitantes de Burgos recuerdan aún hoy como un símbolo de aquel momento de la ciudad. Tras dos décadas de indecisión que resumen el surgimiento del planeamiento y la gestión urbana y las complicadas operaciones urbanísticas que en muchas ocasiones se han llevado a cabo en nuestras ciudades, el solar tiene el

\footnotetext{
${ }^{7}$ Archivo Municipal de Burgos, Expediente AD-5029/1.

${ }^{8}$ Archivo Municipal de Burgos, Expediente AD-4743/1.
} 
destino definitivo de acoger un gran equipamiento cultural encaminado a dinamizar la vida intelectual, científica y turística de Burgos.

No cabe duda de que se trata de un nuevo símbolo, de una nueva imagen a construir en la ciudad y de una nueva referencia para los habitantes que habitan en ella como reflejo de una nueva etapa en la construcción del espacio urbano. Las posibilidades abiertas por la construcción del museo en el marco del amplio proyecto englobado por la importancia de los yacimientos arqueológicos de la Sierra de Atapuerca son muy importantes para la ciudad desde todos los puntos de vista. La adecuada gestión de este centro y sus lazos con la investigación y la divulgación son, en nuestra opinión, la verdadera potencialidad de este proyecto. Un proyecto que ha de ser entendido como un todo desde la perspectiva defendida por los propios investigadores de Atapuerca, un conjunto en el que se mezclen la cultura, el turismo, la ciudad de Burgos y su dinamización, con una actuación urbanística ejemplar y mediante la cual se consiga dotar al núcleo de una verdadera imagen moderna que rompa con la rancia visión de capital de provincia inmutable por la que Burgos viene siendo entendida desde hace ya muchos años.

La imagen del propio museo una vez construido dirá, con el tiempo, si se ha conseguido perpetuar una verdadera referencia urbana en la ciudad que consiga ofrecer una alternativa factible a su espléndida catedral gótica y la gestión y el dinamismo del centro serán responsables, en buena medida, de alcanzar el objetivo previsto desde el punto de vista de la mejora del turismo en esta ciudad media.

\section{BIBLIOGRAFÍA.}

- ANDRÉS LÓPEZ, G. (1999): «De las Ordenanzas Municipales al primer Plan de la democracia: origen y evolución del planeamiento urbano en la ciudad de Burgos», en Boletín de la Institución Fernán González, no 219, pp 415 - 450.

- ANDRÉs LóPEZ, G. (2000): La Castellana. "Ciudad Jardín en Burgos", Editorial Dossoles y Excmo. Ayuntamiento de Burgos, Burgos, 2000, 270 p + 33 láminas cartografía.

- ANTÓN ClAVÉ, S. y LÓPEZ PALOMEQUE, F.(1997): «El turismo como estrategia de promoción y desarrollo de Barcelona», en AGE: Dinámica LitoralInterior, Actas del XV Congreso de Geógrafos Españoles, pp 1111 - 1118.

- ARSUAGA, J.L. y MARTíNEZ, I. (2000): La especie elegida, Ed. Temas de Hoy, Barcelona, $350 \mathrm{p}$.

- BERMÚDEZ De CASTRO, J.Mª (1999): «La Sierra de Atapuerca: un proyecto cultural para el siglo XXI», Museo Nacional de Ciencias Naturales, CSIC.

- BERNAL SANTA OlaLla, B. (1997): «Los diversificados intentos de Burgos por cambiar su tradicional imagen», AGE: Dinámica Litoral-Interior, Actas del XV Congreso de Geógrafos Españoles, pp 1141 - 1147.

- BUSQUETS, J. (1993): «La transformación urbana como proyecto», en $U r$ banismo COAM, $\mathrm{n}^{\circ} 19$.

- CALDERÓN Monge, E., DíEz Simón, E. y MARTÍNEZ ARNÁIZ, M.: El perfil de la demanda turística de la provincia de Burgos, Universidad de Burgos, $201 \mathrm{p}$.

- Cortizo Álvarez, T. (1999): «Las huellas de la renovación actual en las ciudades asturianas», en AGE: El territorio y su imagen, Actas del XVI Congreso 
de Geógrafos Españoles, pp 997 - 1009.

- DELGAdo VIÑAS, C. (1995): Las pequeñas y medianas capitales de provincia en el proceso de modernización del sistema urbano español, Serv. Publicaciones Universidad de Las Palmas de Gran Canaria, 226 p.

- DOMÍNGUEZ RoDRÍGUEZ, R. (Coord.) (1999): La ciudad. Tamaño y crecimiento, Ed. Departamento de Geografía de la Universidad de Málaga y AGE, Málaga, $532 \mathrm{p}$.

- ESTEBAN ALONSO, A. y LÓPEZ LÓPEZ, A. (1989): «El papel de las ciudades medias en España. Presente y futuro», en Urbanismo COAM, $\mathrm{n}^{\circ}$ 6, pp 6 -16.

- JUARISTI, J. (1999): «La postmodernización como estrategia de revitalización urbana: aprendiendo de Bilbao», AGE: El territorio y su imagen, Actas del XVI Congreso de Geógrafos Españoles, pp 1085 - 1097.

- LOBO MONTERO, P. (1998): «La comercialización turística de las ciudades históricas españolas», en Ería, n 47 , pp $281-298$.

- MARTín GIL, F. (1998): «Turismo y economía en las ciudades históricas españolas», en Ería, no 47 , pp $267-280$.

- MARTíNEZ CEARRA, A. (1993): «El Bilbao Metropolitano. Un proyecto de regeneración urbana», en Urbanismo. COAM, $\mathrm{n}^{\circ} 19$, pp 26-30.

- ORTEGA VALCÁRCEL, J. (1999): «El patrimonio territorial: el territorio como recurso cultural y económico», en Ciudades. Revista del Instituto de Urbanistica de la Universidad de Valladolid, $\mathrm{n}^{\circ} 4$, pp $33-48$.

- OTAOLA, P. (1994): «Bilbao 2000: nueva centralidad», en Alfoz, no 109, pp 99-104.

- PASCUAL I ESTEVE, J.M. (1999): La estrategia de las ciudades. Los planes estratégicos como instrumento: métodos, técnicas y buenas prácticas, Ed. Diputación de Barcelona, $366 \mathrm{p}$.

- PIÑOL AlABART, J.Ma . y CÁCERES SILVA, J. (1997): «La renovación urbana como estrategia de proyección de las ciudades medias: el caso de Reus», en AGE: Dinámica Litoral-Interior, Actas del XV Congreso de Geógrafos Españoles, 1189 - 1196.

- TROITIÑO VINUESA, M. A. (1995): «El turismo en las ciudades históricas», en Polígonos. Revista de Geografia, ${ }^{\circ}$ 5, pp 49-65.

- TROITIÑO VINUESA, M. A. (1995): «Turismo y desarrollo sostenible en ciudades históricas», en Ería, no 47, pp 211-227.

- VERA REBOLLO, J. F. y DÁVILA LINARES, M. (1995): «Turismo y patrimonio histórico y cultural», en Estudios Turísticos, $\mathrm{n}^{\circ} 126$, pp $161-177$.

- VVAA. (1998): Atapuerca, un millón de años de historia, Ediciones Plot y Editorial Complutense, Madrid, $240 \mathrm{p}$.

- VVAA. (1998): «Toledo: problemática e implicaciones urbanas del turismo», en Ería, no 47, pp 299 - 325.

- VVAA. (1999): Atapuerca. Nuestros Antecesores, Madrid.

- WOLF, J.P. (1997): «La ciudad entre realidad e imágenes», en AGE: Dinámica Litoral-Interior, Actas del XV Congreso de Geógrafos Españoles, pp 1197 - 1203. 


\section{FUENTES.}

- Ayuntamiento De BuRgos: Consulta Internacional de Ideas para el Solar de Caballería de Burgos, Burgos, 2000.

- AYUNTAMIENTO DE BURGOS: Estadísticas sobre consultas turísticas en las Oficinas de Información Municipal, Concejalía de Turismo y Festejos, Burgos, 2000.

- ArChivo Municipal De BuRgos: Expediente de consulta AD-653/4.

- ARChIVO MuniCIPAL DE BURGOS: Expediente de consulta AD-821/1.

- ARCHIVO MuNiCIPAL DE BuRgOS: Expediente de consulta AD-4743/1.

- ARCHIVO MUNICIPAL DE BURGOS: Expediente de consulta AD-5029/1.

- ARCHIVO MUNICIPAL DE BURGOS: Expediente de consulta AD-5047/4.

- ARCHIVO MUNICIPAL DE BURGOS: Expediente de consulta AD-5256/1.

- ARCHIVO MUNICIPAL DE BURGOS: Expediente de consulta AD-5260/1.

- DIARIO DE BURGOS: Varios números.

- JUNTA DE CASTILla Y LEÓN: Boletín de Coyuntura Turística de Castilla y León. Mayo 2000, Valladolid.

- NúÑez CENTElla, R.: Museo de la Evolución Humana de Burgos. Documento Previo. Memoria, Ayuntamiento de Burgos, Noviembre 1999.

- www.aytoburgos.es

- www.diariodeburgos.es

- www.diariodeburgos.es/atapuerca

- www.atapuerca.geo.ucm.es

RESUMEN: Las relaciones establecidas entre los proyectos de promoción turística de la ciudad y las actuaciones urbanísticas sobre espacios urbanos degradados o infrautilizados se han multipli cado en el conjunto de las ciudades medias españolas en la década final del siglo XX. Concretamente, la construcción de importantes equipamientos, materializados en "edificios-imagen" y, en la mayor parte de los casos, vinculados muy directamente con un amplio elenco de actividades y servicios relacionados con la cultura y el ocio, se ha desvelado como uno de los procesos con mayor capacidad de arrastre desde el punto de vista de la dinamización y mejora de la vida turística de estos conjuntos urbanos. Este artículo pretende contribuir a la reflexión sobre las relaciones entre la imagen urbana de la cultura y el significado de ésta en el turismo, utilizando para ello un análisis detallado de las posibilidades que presenta el Proyecto Atapuerca en la ciudad de Burgos.

PALABRAS CLAVE: Ciudad Media, Turismo, Equipamientos Urbanos, Cultura, Imagen Urbana, Burgos.

ABSTRACT: The links forged between municipal projects aimed at increasing tourism and public works of urban renewal aimed at revitalizing degraded and underused spaces have increased exponentially in all mid-size Spanish towns in the last decade of the twentieth century. Concretely, the creation of infrastructure which is elaborated through buildings which become emblematic and in most cases plugged into a wide variety of activities and services linked to culture and entertainment, has appeared as one of the processes most likely to result in activities that revitalize and improve the tourist industries of all these cities. This article seeks to contribute to the dialogue about 
the relationship between the cultural image of a city on the one hand, and the significance of this image in the tourist industry on the other, by way of a detailed analysis of the opportunities that the "Atapuerca Project" might offer to the city of Burgos.

KEY WORDS: mid-size town, tourism, urban infrastructure, culture, urban image, Burgos.

$\boldsymbol{R} \boldsymbol{E} \boldsymbol{S U} \boldsymbol{M E}$ : À la fin de XXième Siècle, les relations établies entre les projets de promotion touristique et les actions urbanistiques sur les espaces urbaines dégradées ou moins utilisées s'ont multipliées dans les villes moyennes espagnoles. La construction d'importants équipements, faits comme « bâtiments - images » et, dans la plupart des cas, liés directement à activités et services relies avec la culture et le loisir, a été un processus avec une grande capacité de traînement pour la dynamisation et l'améliorement de la vie touristique de ces conjoints urbains. Cet article essaie de contribuer à la réflexion sur les relations entre l'image urbaine de la culture et l'importance de celle-là au tourisme et, pour lui, on utilise une analyse détaillée des possibilités qui présent le «Projet Atapuerca» dans la ville de Burgos.

MOTS-CLÉS: ville moyenne, tourisme, équipements urbains, culture, image urbaine, Burgos 